\section{La dimensión identitaria de las expresiones para- diplomáticas entre Bolivia y Chile: una lectura desde dos otredades ${ }^{*}$}

The identitary dimension of paradiplomatic expressions between Bolivia and Chile: An interpretation from a double otherness.

\author{
Cristian Ovando-Santana* \\ Sergio GonZÁLEZ-MiRANDA ${ }^{* * *}$
}

\section{Resumen}

Se aborda la conformación de identidades locales dentro de la región de Tarapacá, a

Artículo resultado de proyecto FONDECYT REGULAR 1160209 y resultado de proyecto de investigación "las ciencias sociales chilenas y sus perspectivas sobre la proyección fronteriza de Norte Grande", financiado por la Vicerrectoría de Investigación de la Universidad Arturo Prat, código: VRIIP 0112-17.

** Doctor en Estudios Internacionales. Instituto de Estudios Internacionales, Universidad Arturo Prat (Chile). E-mail: covando@ unap.cl. Arturo Prat 2120, Iquique.

*** Doctor en Estudios Americanos. Departamento de Ciencias Históricas y Geográficas, Universidad de Tarapacá (Chile). E-mail: pampino50@gmail.com. Avda. 18 de septiembre 2222, Arica. partir de los vínculos paradiplomáticos que emprenden actores de esta región con el occidente de Bolivia. Para ello, intentamos develar e interpretar el contenido de sus demandas regionales en el marco de algunas coyunturas diplomáticas llevadas a cabo por sus respectivos gobiernos nacionales y ciudades capitales desde el Tratado de 1904 hasta la actualidad. Se sostiene que, en aquellas coyunturas, desde una perspectiva dialógica de la formación de identidades (Lebow 2008), estos actores subnacionales se constituyeron en protagonistas, a partir de reivindicar ciertos valores e intereses comunes a uno y otro lado de la frontera. También, se identifican palabras básicas (Buber 2006) -que definen conceptos pares que permiten la integración o el distanciamiento entre actores obligados a estar relacionados- en los discursos político/ diplomático de Bolivia y Chile.

Palabras clave: doble otredad, paradiplomacia, palabras básicas, actores subnacionales, transfrontera.

\begin{abstract}
This article tackles the constitution of local identities within the Tarapacá region based on the paradiplomatic ties that local actors undertake with the west of Bolivia. With this purpose, we try to unveil and interpret the content of their regional demands in the context of some diplomatic conjunctures carried out by their respective national governments and capital cities, from the Treaty of 1904 up to now. We hold that in those conjunctures, from a dialogic perspective of the creation of identities (Lebow 2008), these subnational actors came to play
\end{abstract}


leading roles since vindicating certain values and interests common to both sides. Also, basic words are identified (Buber 2006)-defining pairing concepts that allow the integration or estrangement between actors forced to be related- in the political/diplomatic speeches of Bolivia and Chile.

Key words: double otherness, paradiplomacy, basic words, subnational actors, cross-border.

\section{Introducción}

Para Edmundo Heredia, "a medida que el hombre va avanzando, poseyendo y conquistando espacios, también va convirtiendo el suelo en territorio, en tanto este último término es el preferido para significar la soberanía de una nación sobre la superficie" (2005:180). Así, los significados posibles que se le atribuyen a los territorios que se constituyen dentro de las regiones fronterizas del Cono Sur, desde la fundación de sus Estados nacionales, parten del reconocimiento de la identidad nacional a través de una visión negativa del otro extranjero (Sahlins 2000.42-43), que se puede calificar de identidad por oposición. Esta visión predominante, se instaló en la academia a través del nacionalismo metodológico, como lo afirma Chernilo: "muchos pensadores del siglo XX pusieron tantas esperanzas en sus indudables cualidades modernizadoras y capacidad para crear bienestar, que terminaron asumiendo que el estado-nación era efectivamente la forma natural de organización de la sociedad en la modernidad (2010:24). A fortiori, a escala de toda la sociedad, como bien lo reflexionó Beck, el nacionalismo metodológico "iguala sociedades con estados-nación" (2002:51). Entonces, las fronteras territoriales de esas sociedades se transformaron también en las fronteras de las disciplinas de las ciencias sociales y humanidades que estudian el tiempo presente. Desde este sesgo, negando al territorio en tanto comunidad regional también se niega esa capacidad que poseen aquellas y las sociedades de propiciar el encuentro transfronterizo entre ellas "en una específica manera de entablar relaciones internacionales" (Heredia 2005: 180).

La perspectiva que pone énfasis en la homogeneidad del territorio nacional, los límites fronterizos y la soberanía que los cautela, es la que, como veremos más adelante, hace eco en la conformación de las identidades políticodiplomáticas.

Por lo anterior, y en contrapunto, adherimos a una corriente dialógica de la construcción de identidades, que busca evitar la binarización entre el yo y el otro, tendencia propia del pensamiento moderno de las Relaciones Internacionales (Walker 1993,1995; Ashley 2009). Desde la filosofía, Martin Buber, nos dice que para el ser humano el mundo es doble:

"Las palabras básicas no son palabras sueltas, sino pares de palabras. Una palabra básica es el par yo-tú. La otra palabra básica es el par yo-eso, en el que se puede introducir la palabra él o ella en lugar de eso sin cambiar la palabra básica. De ahí que también el yo del ser humano sea doble. Pues el yo de la palabra básica yo-tú es distinto al de la palabra básica yo-eso" (2006: 11).

También el par "nosotros-ustedes" tiene su sombra con el par "nosotros-otros" (Todorov 1991), donde en lugar de "otros", en el campo de las relaciones internacionales y, más aún, en relaciones transfronterizas, pueden estar 
las palabras "vecino", "hermano" e, incluso, "enemigo". Surge así otra palabra básica: "amigo-enemigo" (Schmitt 1998). Este par parece ser más adecuado cuando dos países enfrentan un "casus belli", pero no lo es en absoluto en situación de normalidad, que es lo habitual en las relaciones transfronterizas. Hacer un ejercicio escogiendo una palabra básica que establezca la menor distancia entre las identidades de actores subregionales en Regiones Asociativas de Frontera (Boisier 2003), es, sin duda, un desafío disciplinario.

En suma, las teorías dialógicas sobre la formación de identidades, desde las palabras basadas en la alteridad, se centran en una definición cambiante del ser. Oponiéndose a las aproximaciones que sostienen la construcción monolítica de la identidad del yo, abordan la construcción del sujeto considerando que aquel se encuentra en un continuo proceso de interacción, desde una perspectiva relacional (Bourdieu 1994).

El objetivo de este artículo consiste en problematizar, siguiendo el debate sobre la formación de identidades en las teorías de las relaciones internacionales críticas (Guillaume 2011, Hopf 2002), la dimensión identitaria de algunas expresiones paradiplomáticas emprendidas entre las regiones del norte Chile y el centro oeste de Bolivia. Se trata de un territorio que, en cierta forma, se enmarca en el área centro sur andina (Albó et al 1996), identificada por la antropología y la etnohistoria andinas. Para ello, consideramos algunas experiencias y discursos que evidencian complementariedad $y$, en ocasiones, oposición de intereses y valores con sus respectivos Estados, a partir de las demandas regionales que realizan a sus capitales en ciertas coyunturas diplomáticas de las complejas relaciones entre estos dos países. También consideramos la afinidad ideológica y complementariedad económica que comparten con sus regiones vecinas allende la frontera, con quienes han planteado un futuro en torno al desarrollotransfronterizo. Complementariamente, identificamos palabras básicas (Buber 2006) -que definen conceptos pares que permiten la integración o el distanciamiento entre actores obligados a estar relacionados- en los discursos político/diplomático de Bolivia y Chile.

\section{Aspectos metodológicos}

En primer lugar, describiremos brevemente algunas premisas metodológicas que guían esta investigación, a saber:

Para acercarnos a este fenómeno, utilizaremos la estrategia genealógica. Ella "fue utilizada, inicialmente, para el cuestionamiento de las concepciones dominantes en nuestra disciplina" (Cornago, 2015:223), como es el caso de la articulación de ideas e identidades en política internacional, desde el simplificador logo-centrismo y sus respuestas, encarando estas discusiones desde una perspectiva más 'dialógica que dialéctica de la formación de las identidades (superar la idea nacionalextranjero), rescatando el "lado positivo de la alteridad" (Rodríguez 2015).

La perspectiva genealógica (Cornago 2015:225 y ss.), aspira a desplegar un procedimiento de estudio, basado en la investigación de los archivos y los registros más dispares del pasado, que intentan desentrañar el modo en que aquello que reclama nuestra atención, en nuestro caso lo que aconteció y acontece en la frontera norte en cuanto a la formación de 
identidades desde el despliegue internacional de actores sociales, fue y sigue representándose desde de una determinada manera u otra. Por tanto, se trata de "mostrar el modo en que, a través de las cambiantes relaciones de poder a lo largo de la historia, pero siempre de manera contenciosa, unas formas de saber, de decir, o de hacer, junto a las formas de la subjetividad que le son propias (...) prevalecieron sobre otras (Cornago 2015:225).

La genealogía como estrategia de análisis del acontecer internacional en la frontera, busca entender cómo éste fue exponiéndose, a lo largo de la historia del presente, como una actividad preferente del Estado, pero omitiendo otras formas, discursos y prácticas que también reivindican un quehacer. Por ello, la genealogía, "pone el énfasis en la singularidad de los acontecimientos, así como en los discursos silenciados" (Aguirre 2001: 206).

\section{La construcción de identidades político- diplomáticas desde dos lecturas.}

\subsection{La lectura nacional}

Las corrientes racionalistas ${ }^{1}$, implícitamente se han orientado por opciones filosóficas de tendencia kantiano-hegeliana, que defienden la creación del otro como una necesidad para la formación y refuerzo de la identidad estatal (Pintado 2015: 93). La invariable identidad egoísta del Estado surge de esta oposición

Las visiones racionalistas de la actividad internacional - realistas, neorrealistas, transnacionalistas- la diplomacia u otros actores, explican el intercambio como un mero juego de actores que busca la conciliación de intereses- valores o desde la manipulación o instrumentalización del otro (una relación sujeto-objeto) para alcanzar sus objetivos, guiados por la Razón de Estado, desde la utilidad o las ganancias que aporta la cooperación. binaria traducida en una conducta marcada por la desconfianza hacia el otro extranjero. En cambio, las opciones idealistas y todas sus derivaciones hasta llegar a las posiciones reflexivas adhieren a la corriente filosófica habermasiana, que subraya el papel del diálogo para evitar la binarización entre el Yo y el Otro (Pintado 2015) y privilegian la alteridad como un elemento clave del entendimiento y la superación de posiciones fatalistas entre actores obligados a estar relacionados.

Desde este debate en que predominan las corrientes tradicionales racionalistas de formación de identidades, las complejas relaciones entre Chile y Bolivia dejan en evidencia la manifestación de distintas identidades político/diplomáticas a lo largo de su historia de más de cien años, si tomamos como punto de partida el Tratado de Paz y Amistad de 1904. Éstas expresan diferentes formas de afrontar el centenario conflicto que las aqueja y de concebir el territorio epicentro de la Guerra del Pacífico. Destacamos en el caso de Bolivia las emotivistas, integracionistas y practicistas (Andaluz 2002, Francisco 2009; González y Ovando 2015). La primera, marcada por el reivindicacionismo y la negociación de suma cero como estrategia para abordar negociaciones con Chile, si bien expresa la frustración de los representantes del estado boliviano, se extiende a la clase política y la sociedad en general, a causa de la denominada pérdida de la cualidad marítima derivada de la usurpación del litoral. Para ella, desde una perspectiva westfaliana, el territorio nacional se entiende como un bloque de espacio uniforme, en parte usurpado por el vecino agresor, y en el que se expresa una particular aprensión por la frontera contigua con Chile. Esta expresión se manifiesta a través del uso sistemático en 
los discursos emotivistas de la palabra básica: "amigo-enemigo" (Schmitt 1998), en tanto predomina en toda argumentación emotivista el uso de las categorías agresor -agredido, usurpador- usurpado, victima -victimario, etc. La segunda, más próxima a las elites económicas vinculadas a algunos gobiernos de turno de sello liberal, busca la complementariedad por la vía de acuerdos comerciales entre Chile y Bolivia y la negociación mutuamente beneficiosa en torno al canje territorial (Orias 1997; Salazar,2006), por tanto, si bien entiende el territorio nacional como un espacio uniforme con una frontera física delimitada con claridad, se abre a considerarlo una moneda de cambio a partir de negociaciones entre autoridades de ambos países. Entre los actores que adhieren a esta identidad, por ejemplo, predomina la palabra básica nosotros-ellos, en tanto competidores o actores egoístas que comparten intereses, pero poseen identidades propias. En efecto, desde la perspectiva de relaciones diplomáticas entre dos Estados $u$ actores motivados por el practicismo no queda claro si se reconstruyen sus respectivas identidades, ya sea desde el intercambio dialógico o desde sus propiedades intrínsecas, prevaleciendo identidades competitivas (egoístas), distintas.

La tercera, más sui generis y contemporánea, ensaya propuestas de desarrollo trinacional en torno a la integración entre Chile, Perú y Bolivia como salida a este histórico litigio y proviene de la intelectualidad boliviana (Anaya 1987, Araníbar 1999); concibe el territorio como un espacio en que se reconoce la presencia e importancia de procesos sociales transfronterizos. Desde esta premisa, reivindica dinámicas cooperativas entre regiones allende la frontera chileno-boliviana como una forma de afrontar el conflicto centenario. Desde estas dinámicas, se infiere la formación de identidades desde perspectivas dialógicas que privilegian, como señalamos más arriba, el uso de palabras como el par "nosotros-otros" (Todorov 1991), donde en lugar de "otros", en el campo de las relaciones transfronterizas, pueden estar las palabras "vecino", "hermano. Se refiere a una palabra básica que establezca la menor distancia entre las identidades de actores que habitan la franja fronteriza.

En el caso de Chile, encontramos una identidad política surgida desde el momento original, el Tratado de Paz y Amistad de 1904, marcada por las estrategias de statu quo ante ofensivas bolivianas en torno a la reivindicación marítima, el apego estricto al derecho internacional y la defensa histórica de la integridad territorial (Barros, 1970; Colacrai y Lorenzini 2005, Ross 2016). Esta identidad definida por la protección del territorio resultante de las anexiones producidas tras la Guerra del Pacífico (Cabrera 2009), se fue gestando y perpetuando por la enunciación de un discurso oficial que arranca en este hito, y que recoge un par de palabras que expresan antagonismo. Por ejemplo, la dualidad sarmientina "civilización y barbarie" surgió durante y después de la Guerra del Pacífico entre los contendientes, donde para los chilenos los peruanos y bolivianos eran los "bárbaros" $y$, por el contrario, para éstos los "bárbaros" eran los chilenos. Si bien el contenido de ese par de palabras podría ser diferente para cada contendiente, lo relevante es que en ambos casos existía un intento "deshumanización del otro" (Schmitt 1954), incluso esa palabra básica se expresó en un imaginario que fue ilustrado por la prensa de la época de los tres países, en especial en revistas o magacines (Ruzet al 2006), donde se muestra al "civilizado" y al "bárbaro", según la mirada de cada país. Palabra básica 
"civilización y barbarie" que fue llenándose de contenido a escala de la sociedad, incluyendo las elites que dirigían la política exterior chilena y boliviana, las que justificaban sus acciones durante el periodo posbélico desde el ideario liberal o conservador. Solo por mencionar un personaje de cada país, tenemos a Manuel González Prada (1941,1976), peruano, Roberto Querejazu Calvo (1998), boliviano, y Francisco Encina (1963), chileno. Idearios que han sufrido cambios ideológicos con el devenir de los siglos veinte y veintiuno, pero la palabra básica persiste con nuevos contenidos y autores.

Sobre el territorio, desde una perspectiva westfaliana, el espacio nacional se representa como un bloque de espacio uniforme, y en el que se expresa una particular aprensión por la frontera contigua con Bolivia de parte de la autoridad, a partir de la anexión territorial consecuencia de la Guerra del Pacífico y las ocasionales reivindicaciones territoriales de parte de ambos países.

En suma, en el caso de Bolivia, se trata de una discusión en torno a cómo se interpreta al "otro" responsable de su enclaustramiento, "el chileno" (Andaluz, 2002). Esta construcción parte por sentenciar a Chile como un país victimario y, por añadidura, moralmente condenable. De ese modo, la identidad "emotivista" cierra todas las posibilidades dialógicas de entendimiento (González y Ovando 2016). Muchos intelectuales bolivianos (Escobari 1978, Ponce 1998; Andaluz 2002) vieron y ven en el enclaustramiento boliviano un peligro al estado-nacional, puesto que con dicho enclaustramiento se habría heredado una rivalidad y percepción de amenaza histórica construida desde un sentimiento vital, que se transformaría en una fuerza profunda para el derrotero de su política exterior. En cambio, las otras dos perspectivas, sobre todo la integracionista, se abren a opciones distintas de la construcción de identidades, siguiendo el supuesto dialógico que señala que “los Adversarios 'Nobles' aprenden a practicar 'paciencia ' y 'consideración' en sus relaciones con otros" (Lebow 2008).

En el caso de Chile, la política del statu quo con que se ha abordado la demanda marítima, negando toda posibilidad de negociación más allá a lo dispuesto en el Tratado de Paz y Amistad de 1904, ha contribuido al distanciamiento de posiciones entre diplomáticos de ambos países y tendido a la consecuente binarización de la construcción de estas identidades.

Con todo, las características de cada una de estas identidades, expresan las visiones de mundo, representaciones del territorio intereses, preferencias y prioridades estratégicas, enunciados por palabras que dan cuenta de las posibilidades de dichas identidades, a partir de una serie de actores partícipes de un juego diplomático que trasciende este campo, para trasladarse a las sociedades nacionales $y$, en ocasiones, a las sociedades regionales de ambos países. Esta última afirmación es plausible si partimos del supuesto que señala que la representación de la identidad colectiva de las comunidades políticas que se proyectan internacionalmente hacia sus vecinos, debe considerar cómo se auto perciben las regiones en tanto comunidades políticas que reclaman un rol más protagónico a la comunidad mayor, el Estado (Cornago 2010: 116,117 y 118).

\subsection{La lectura regional transfronteriza}

En todo estudio sobre zonas fronterizas de Estados en construcción, debe considerarse "la 
importancia de los grupos locales como agentes y actores históricos en la formación de identidades y territorios" (Sahlins 2000: 42). Estos actores, desde la evidencia moderna europea entre los siglos XVII y XIX, han negociado sus intereses y sentido de pertenencia al lugar con los Estados naciones en formación, al asentarse y reproducirse sus identidades en el espacio. Así, la dimensión regional del entramado identitario de las naciones, deja en evidencia, entre otras manifestaciones, el quehacer de actores paradiplomáticos o regionales que expresan la voluntad histórica de buscar a través de vínculos internacionales y transfronterizos oportunidades para el desarrollo de sus regiones periféricas (Sahlins 2000; Ovando y González 2014). Estos últimos -intentaremos demostrar a través de una serie de discursos que expondremos en el siguiente apartado- tienen otra lectura del conflicto por el enclaustramiento o mediterraneidad boliviana, en tanto que ven en sus alternativas de solución una oportunidad para su alicaído desarrollo. En efecto, en el caso de Tarapacá y Oruro, han visto en la integración física a través de líneas férreas, carreteras para vehículos de alto tonelaje y últimamente corredores bioceánicos, una oportunidad para su desarrollo, prescindiendo de los ocasionales pleitos diplomáticos que sostienen sus capitales y que afectan las posibilidades de cooperación fronteriza entre ambas sociedades regionales, o aprovechando estas coyunturas para hacer sus propias demandas a las respectivas capitales (González, 2011, González y Ovando 2011; Ovando y González 2014).

Por tanto, podemos conjeturar que las regiones de Tarapacá y Oruro y sus localidades cercanas (La Paz; Arica, etc.), han emprendido históricamente dinámicas transfronterizas en tanto regiones periféricas que han sido clave en la constitución de sus identidades. Sostenemos este argumento desde dos premisas. Por una parte, continuaron y continúan sus vidas cotidianas y ligadas lejos de todo pleito diplomático, pero sabiendo que allí existía, continuó existiendo y existirá por mucho tiempo una frontera, porque su ontología como sujetos paradiplomáticos depende de ella, y, por otro lado, han aprovechado algunas coyunturas críticas de este litigio que enfrenta a ambas capitales para plantear sus propias demandas regionales.

Si bien estas premisas no suponen que estos actores locales expresen estrategias de "acomodación territorial" (Moreno 2004), en tanto movimientos etnoterritoriales que desafían la delimitación de las fronteras establecidas por los estados, sí implica el surgimiento de una identidad transfronteriza distintiva a tener en cuenta.

Una clave relevante en la discusión sobre actores paradiplomaticos es la identidad regional: "para que una provincia pueda tener un rol regional o internacional debe consolidar su imagen" (Zeraoui 2016: 29). En nuestro caso, se trata de una identidad local que si bien no es irrendentista ${ }^{2}$, pues no se oponen abiertamente a la cultura nacional y al poder central, el abandono que padecen del centro -fenómeno extendido en el continente y que conlleva la construcción de periferias en las fronteras (Serje de la Ossa 2017)- las ha llevado a forjar una identidad marcada por dos elementos. Por un lado, una ideología o sentimiento de rechazo ante el abandono y relegación desde las capitales

\footnotetext{
Como señala Zeraoui, siguiendo a Rachik (1995), "existen dos identidades: la dura y la blanda. La primera se refiere primordialmente a los irredentismos que se oponen abiertamente a la cultura nacional, mientras que la identidad blanda existe en todas las provincias o regiones y es lo que permite diferenciar un Estado de otro, sin hacer de estas diferencias antagonismos" (2016: 29).
} 
(Soza-Amigo y Correa 2014), que genera en ocasiones reacciones contestataria hacia éste, y una perspectiva de futuro en torno a proyectos desarrollo transfronterizo. En segundo lugar, en esta identidad el conflicto centenario por la salida soberana al mar de Bolivia no constituye un elemento relevante, en tanto un tema que oponga a las regiones de uno y otro Estado, al contrario, su solución es prevista como un aliciente para el alicaído desarrollo de sus regiones y su proyección transfronteriza.

\section{La construcción del territorio desde dos otredades.}

Desde el giro espacial de las ciencias sociales (Harvey 1985, Lefebvre 1974, Appadadurai 1996), se ponen en entredicho las representaciones identitarias ancladas en la soberanía territorial (nacional), como es el caso de las identidades políticas emotivista boliviana y la del statu quo chilena. Esta perspectiva, nos permite comprender la proliferación de actores sociales que desarrollan sentimientos de pertenencia e identidades múltiples, ubicándose en esta tendencia los colectivos paradiplomáticos. Desde esta lectura destacamos que, escudriñando en aquellas, es posible reducir la homogeneidad nacional del Estado, sobre todo en estados unitarios como es el caso de Chile y además nos permite reconocer el componente transfronterizo de la discusión sobre las identidades (Giménez 2009).

\subsection{Identidad y paradiplomacia desde dos otredades}

En el ámbito de las investigaciones sobre la frontera como territorio que se extiende entre dos naciones, y que se vincula con las prácticas y discursos paradiplomáticos (Amilhat Szary 2016; Cornago 2016), surge un campo interdisciplinar que estudia las expresiones de paradiplomacia transfronteriza desde concepciones fenomenológicas y discursivas de la frontera. Estas investigaciones abordan estudios de casos sobre cooperación transfronteriza entre autoridades subnacionales y otros actores no estatales, profundizando en la territorialidad que despliegan los sujetos políticos regionales (paradiplomacia), indagando en algunos retazos de la historia que nos pueden mostrar expresiones y subjetividades no estatales, como es el caso de grupos étnicos, elites económicas y gobiernos subnacionales, quienes propician otras formas de enunciar y entender el acontecer en la frontera.

Como señalamos someramente al inicio de este artículo, proponemos en esta contribución concebir la identidad paradiplomática en torno a distintas dimensiones de la integración chileno - boliviana desde dos otredades (Morales y Reyes, 2016) y desde el enfoque dialógico presente en los nuevos estudios diplomáticos (Constantinou, 2013; Cornago, 2016; Duran, 2012). Para ello, intentaremos ir registrando evidencias históricas de la conformación de estas identidades territoriales, a partir de ciertas coyunturas diplomáticas que reúnen a los agentes diplomáticos de los dos países y en las cuales se expresan los contenidos y enunciados de estas identidades de anclaje geográfico.

Como tendencia general, los estudios paradiplomáticos se: "han concentrado en señalar la diferenciación que se tiene con respecto a la identidad nacional del Estado donde se encuentran, lo cual les motiva a desarrollar una agenda propia" (Morales y Reyes 2016: 87), desatendiendo otras dimensiones 
de análisis que singularizan los fenómenos paradiplomaticos. En efecto, para estos mismos autores, además de esta diferenciación, debería simultáneamente "observarse la construcción de las relaciones que se realizan sobre la similitud de los lazos culturales con los agentes seleccionados de destino" (Morales y Reyes 2016: 87).

Aparejado a este último argumento, cuando nos aproximamos a los fenómenos paradiplomáticos, el debate reflexivo en torno a la idea de las dos otredades, nos aporta un instrumental teórico metodológico para poder interpretar el surgimiento de sus identidades de una manera distinta.

Esta dimensión teórica señala que el grado en que se comparten y diferencian los componentes de la identidad regional demanda ser analizado a la luz de dos Otredades: la del Estado de origen y la del agente de destino de la actividad paradiplomática (Morales y Reyes, 2016:89-90), en el caso de Oruro en referencia a Tarapacá y La Paz. En cuanto al grado en que se comparten y diferencian los componentes de la identidad con el agente de destino, a Oruro y Tarapacá los une el sentimiento de alienación territorial ${ }^{3}$ que padecen respecto al abandono y relegación histórica de manos de los respectivos centros políticos. Como queda en evidencia en muchísimas notas de prensa y discursos regionales que a continuación analizaremos, también el padecimiento de un centralismo

En cuanto a los rasgos identitarios que comparten con los agentes de destino, el guion "alienación territorial" permite orientar la discusión sobre las posibilidades de construir identidades paradiplomáticas transfronterizas. Surgen así motivaciones de orden simbólico vinculadas a cómo se auto perciben distintas regiones periféricas en tanto comunidades políticas que reclaman un rol más protagónico a la comunidad mayor, el Estado (Cornago 2010: 116,117 y 118). agobiante asociado al abandono de Oruro y Tarapacá que excluye su identidad territorial diversa, negándoseles poder, autonomía política y participación relevante en la definición de su desarrollo (Valenzuela 1999). Consideramos además que su identidad paradiplomática se sostiene desde la falta de perspectivas para sostener estrategias de desarrollo de cara a las fronteras o con una perspectiva transfronteriza que considere - en su caso- el trazado de corredores bioceánicos. También destacamos "la construcción de las relaciones que se realizan sobre la similitud de los lazos culturales con los agentes seleccionados de destino" (Morales y Reyes 2016:87). En nuestro caso la similitud es relevante: tiene el componente ancestralhistórico reivindicativo que proviene inclusive desde antes de la Colonia y, a la vez, emergente de carácter transfronteriza que rescata las elites económicas y políticas regionales de ambos países (Oruro y Tarapacá). Éstos reclaman por desigualdades económicas y por el deterioro de la representatividad estatal producto del abandono en que las sumen.

Estas manifestaciones las abordamos desde la premisa que señala que "el establecimiento de relaciones diplomáticas entre dos Estados reconstruye sus respectivas identidades, aunque ambos tuvieran ya una identidad distinta (Morales 2015:7, 8,9).

¿Cómo se aborda esta doble otredad estudiar expresiones paradiplomáticas?

para

Discutir la formación de identidades propias de actores paradiplomáticos, sin caer en la relación entre identidad ${ }^{4}$ y procesos de regiones

Paquin (2004:73-94) plantea que la paradiplomacia identitaria, una estrategia internacional llevada a cabo por parte de movimientos nacionalistas dentro de estados multinacionales para reivindicar 
secesionistas (Paquin 2004:73-94), puede resultar confuso, desviando la discusión hacia los alcances de la protodiplomacia, algo alejado de nuestra propuesta 5 . Para evitar este problema, nos guiaremos, como señalamos, por la idea de alienación territorial (Gibbins 1980, Henry 2000, Lawson 2005) como motivación fundamental para que actores paradiplomáticos desde la alteridad con otros que también la padecen como es el caso de las regiones de Tarapacá y Oruro de Chile y Bolivia, - van construyendo discursivamente una identidad distintiva a la de sus respectivas naciones, aunque reconociendo su soberanía territorial.

La formación de identidades paradiplomáticas, surge de "desigualdades económicas o bien crisis de identidad (y frecuentemente ambas) en función de que algunos grupos subnacionales dejan de sentirse representados por sus autoridades estatales" (Sarquís 2013: 90). En nuestro caso, se trata de una crisis de identidad que apunta a la persistencia, con mayor o menor énfasis de manera intermitente, de un sentimiento de abandono de parte del centro político (Ovando y González 2014) y el padecimiento de un centralismo agobiante (Véliz 1980, Podestá 2004, Valenzuela 1999).

su lengua, cultura y tradiciones, junto a privilegios políticos, "refuerza el nacionalismo de los movimientos subestatales y enfatiza la fragmentación nacional” (2004: 74). Éstos dependerán, por ejemplo, de la ideología del gobierno nacional de turno, de la opinión pública del momento, pudiendo ser más o menos proclives a la aceptación de las minorías y sus reivindicaciones identitarias.

Término que se refiere a "la conducta de las relaciones internacionales por un actor no central del gobierno que tiene como objetivo establecerse plenamente como Estado soberano". Protodiplomacia "representa una práctica diplomática preparatoria para una futura secesión y el reconocimiento diplomático internacional de tal ocurrencia (Duchacek 1988, en Tavares 2016:38,39, [traducción propia]).
En cuanto a la construcción de identidades desde la otredad, a partir de un enfoque dialógico ${ }^{6}$, lo que se busca desentrañar es cómo se constituyen sujetos - en nuestro caso sujetos (para) diplomáticos - a partir del compromiso con el "otro diplomático", entendido como un 'sujeto' cuya sola presencia involucra el verdadero cuestionamiento del propio ser en un proceso de reconfiguración de subjetividades mutuas (Cornago 2016:136).

En consecuencia, siguiendo a Morales y Reyes (2016), el sentido de pertenencia o de diferenciación hacia cualquier Otredad, por ejemplo de actores paradiplomáticos de Tarapacá, ya sea hacia el Estado del que forma parte o hacia el comité cívico o cámara de comercio orureños, con los que comparten ciertos valores, padecimientos y proyectos, contribuyen a moldear -ya sea interiorizando o rechazando atributos- la identidad del agente, al grado que hay quienes afirman que la identidad se mantiene más por las relaciones sociales que por sus propiedades intrínsecas (Mitzen 2006).

Este enfoque teórico se contrapone a las visiones racionalistas de la diplomacia que explican el intercambio diplomático y sus identidades como un mero juego de actores que busca la conciliación de intereses- valores o desde la

El siguiente párrafo de Lebow $(2008: 5,6)$ refleja este debate sobre la construcción de identidades: desde premisas dialógicas: "Nietzsche ofrece la proposición general que la buena vida humana es fundamentalmente dialógica en carácter. Este diálogo descansa en la premisa que los interlocutores mantienen verdades metafísicas opuestas y afirma el antagonismo y la naturaleza insegura de estas verdades. Los Adversarios 'Nobles' aprenden a practicar 'paciencia ' y 'consideración' en sus relaciones con otros. El concepto de diálogo de Nietzsche a su vez influenció a Jürgen Habermas, para quien ética y verdad sólo pueden surgir a través de interacciones significativas con otros basados en el principio y práctica de equidad". 
manipulación o instrumentalización del otro (una relación sujeto-objeto) para alcanzar su objetivo en clave Razón de Estado. Estas posibilidades de los estudios diplomáticos, desde un criterio epistemológico, Cornago (2016b:136), siguiendo a Constantinou, lo resume así:

"cualquier concepción del conocimiento diplomático debería tomar en cuenta las experiencias de los diplomáticos con el compromiso del "otro diplomático", ya sea consideradocomo 'objeto' puestoenunaposición observable desde fuera de las encerradas fronteras del sí mismo o alternativamente como un 'sujeto' cuya sola presencia involucra el verdadero cuestionamiento del propio ser en un proceso de reconfiguración de subjetividades mutuas".

\section{Formación de identidades paradiplomá- ticas en el territorio transfronterizo desde la enunciación de palabras.}

Ya descritos la problematización, aspectos metodológicos y recorrido teórico que guía esta investigación, en este apartado final desarrollaremos el análisis de los discursos diplomáticos y paradiplomaticos. Argumentamos que coexisten distintas lógicas y sentidos de la actividad internacional a distintas escalas; no obstante que la diplomacia oficial a través de sus discursos trata de colmar el campo semántico que representa este quehacer, aunque desde los enunciados de actores paradiplomaticos, como veremos en este apartado, se evidencian otras posibilidades que intentamos identificar a través de captar palabras básicas (Buber 2006) -que definen conceptos pares que permiten la integración o el distanciamiento entre actores obligados a estar relacionados- en los discursos político/ diplomático de Bolivia y Chile.

Desde la perspectiva reflexiva, como hemos señalado más arriba, las identidades son construcciones derivadas de prácticas discursivas que construyen los objetos a que se refieren. Son entes discursivos, es decir, no existen más que en y a través del discurso, en tanto son nombres, significantes que homogeneizan una multiplicidad (Sánchez y Zapata 2014: 94). Las principales diferencias, entre aquellas y las perspectivas más moderadas dentro de la teoría de las relaciones internacionales, son de carácter ontológico, apuntando al papel, más o menos relevante, que le asignan a la alteridad para la construcción de las identidades. Para el constructivismo moderado, por ejemplo "Wendt enfatiza la necesidad del otro para la construcción del yo (2003: 511), acepta también la existencia de identidades previas a ese encuentro con la alteridad (...) (Morales 2015:8). En cambio, para los enfoques posestructuralistas, "son las prácticas discursivas socialmente construidas las que generan cualquier concepción de la identidad (Hansen, 2006: 24-25).

Entrando en nuestro caso, el territorio que comprende la región de Tarapacá y su proyección fronteriza hacia Bolivia es, sin dudas, acotado, porque las fronteras nacionales ejercen una fuerza centrípeta, como si curvaran el espacio, atrayendo los fenómenos hacia sus bordes, especialmente cuando se trata de conflictos, litigios o incidentes. El término "vecino" emerge con cierta neutralidad, propio del habla e identidad diplomática, porque las "relaciones vecinales" son las que refieren a las "relaciones bilaterales" entre países que comparten fronteras. Sin embargo, es un habla 
distante y ajena (exo-denominaciones) de la vida propia de la franja fronteriza, más cercana a la identidad paradiplomática, donde existen redes comerciales, familiares y étnicas a uno y otro lado del límite establecido por los estadosnacionales, además de municipios fronterizos, elites locales y comités cívicos de las ciudades que se proyectan allende la frontera, entre otros.

¿Cuál es el habla que las comunidades utilizan (endo-denominaciones) para definir a sus similares transfronterizos? ¿Cuál es la palabra básica?

Por ejemplo, el diario El Tarapacá de lquique, del lunes 26 de mayo de 1958, señalaba que se encontraba sin novedad en Oruro la caravana de orureños ${ }^{7}$ que había cruzado los Andes y llegado hasta lquique, realizando una riesgosa travesía para demostrar la necesidad de una carretera para camiones entre ambas ciudades y regiones (González, 2012; González y Ovando, 2011).

Este recibimiento, que en muchos de sus aspectos fue casi similar al brindado por la población iquiqueña a su arribo a esta ciudad, obligó a los dirigentes de la caravana a formular declaraciones en el sentido de que, si bien las manifestaciones que en esos momentos le brindaba casi toda la ciudadanía de Oruro, que se volcó a su paso por las calles eran similares a las que se registraron en lquique, ellos tenían la obligación de decir, comparativamente, que el recibimiento iquiqueño los había emocionado mucho más, por cuanto fue la expresión llana y cordial de un pueblo hermano y tuvo más calor humano y más amistad, sin desmerecer por ello

para profundizar en la historia regional y el contexto diplomático de las caravanas de la amistad ver: González (2012); González y Ovando (2011), para iniciativas posteriores(1960-1990) de la misma índole ver: Sánchez,(2016) el grandioso recibimiento de que eran objeto en esos momentos.

Posiblemente, ese año de 1958 en el juego propio de identidades paradiplomaticas la palabra básica nosotros-usted devino en nosotros-hermanos. Sin embargo, nadie imaginaría que cuatro años después, pese a las constantes demandas regionales por concretar este proyecto de integración (Ovando y González 2012), la diplomacia de ambos estados-nacionales cambió la palabra básica de los actores subnacionales de las regiones de Oruro y Tarapacá, hacia otra palabra básica propia de la identidad diplomática emotivista, boliviana, y del statu quo, chilena: nosotrosadversarios. Surgió el conflicto por las aguas del río Lauca (González et al 2016), como un eufemismo de la demanda marítima boliviana $y$, la frontera comenzó a ejercer esa fuerza centrípeta que lleva al incidente diplomático, determinando el contenido de las identidades de los actores paradiplomaticos y diplomáticos en juego por largo tiempo.

El diario La Defensa de Arica del 3 de mayo de 1962, nos relata que el consulado de Chile en la ciudad de Potosí fue apedreado por una turba.

Santiago 3.- La Cancillería confirmó ayer en la tarde que el Consulado chileno en la ciudad boliviana de Potosí fue apedreado por una turba de manifestantes.

La Cancillería se puso en contacto con la Embajada de Brasil, país que se ha hecho cargo de los asuntos chilenos en Bolivia, a fin de que pida garantías para el personal consular chileno que continúa en territorio boliviano después de la suspensión de las relaciones diplomáticas."

Claramente, las querellas a escala del estadonación con sus discursos diplomáticos movilizan a los actores subnacionales, reemplazando la palabra básica. Bolivia puso en 1962 fin a las relaciones diplomáticas con Chile y, con ello, 
truncó el sueño orureño-tarapaqueño de una integración física en busca de un desarrollo transfronterizo compartido, expresándose $\mathrm{y}$, consolidándose, la histórica identidad chilena en torno al statu quo y por largo tiempo la emotivista boliviana9.

Posteriormente, en 1975 se iniciará nuevamente el acercamiento entre Bolivia y Chile que llevará al famoso "abrazo de Charaña" que reanudará las relaciones diplomáticas, durante los gobiernos de los militares Banzer y Pinochet, respectivamente. Acercamiento, a escala de los estados nacionales que, a su vez, terminará con un rompimiento diplomático en 1978, que se extiende hasta la actualidad. La prensa recoge los cambios de actitudes y palabras básicas en esos cuatro años de negociación (González y Ovando 2015).

Recogemos solamente un incidente del año 1975 que demuestra cómo los litigios diplomáticos a la escala nacional suelen tener por resultado "incidentes en las fronteras".

El diario La Defensa de Arica, del lunes 13 de enero de 1975, se refiere a una mutua expulsión de ciudadanos bolivianos desde Chile y de chilenos desde Bolivia, supuestamente por encontrarse indocumentados.

La Paz- El Gobierno boliviano expulsará ciudadanos chilenos sin documentación, en reciprocidad con la expulsión de bolivianos de Chile, anunció aquí el Subsecretario de Inmigración, Rodolfo Greminger, quien calificó de "Inamistosa" la actitud del vecino país.

Se trata de aquella identidad que se centraba en dejar tal cual las cosas con Bolivia según disponía el Tratado de Paz y Amistad de 1904

9 Se trata de aquella identidad boliviana que buscaba una solución a su enclaustramiento de parte de Chile, sin compensación alguna de su parte
"En realidad estamos procediendo ya en ese sentido", dijo el funcionario, explicando que la mayor parte de los casos se trata de "meretrices chilenas", que existen en gran cantidad en esta ciudad".

La prensa matutina de ese año (1975) local denunció que veinte bolivianos fueron expulsados de territorio chileno, sin darles tiempo a traer consigo sus enseres personales.

De acuerdo con las versiones periodísticas, los expulsados, que llegaron a $\mathrm{La} \mathrm{Paz} \mathrm{en}$ condiciones precarias, residían varios años en Chile.

Señalaron que no se recibió a nivel gubernamental ninguna explicación oficial del Gobierno chileno.

Un Comité de Repatriación se formó aquí para ayudar a los bolivianos que llegaron de Chile. El Gobierno proyecta otorgarles tierras en zonas de colonización para darles oportunidad de "rehacer" su vida, según declararon voceros del Ministerio del Interior.

Esta noticia tiene elementos similares a dos incidentes en la frontera de Colchane o Pisiga, el primero, entre aduaneros y policías bolivianos que fueron supuestamente descubiertos robando un camión en territorio chileno por carabineros chilenos y fueron detenidos; el segundo, se trató de carabineros chilenos que supuestamente ingresaron ilegalmente y armados en territorio de Bolivia.

En el primer caso, La Cancillería de Chile señaló que los soldados en actos sospechosos violaron la soberanía chilena portando armas, por lo que fueron detenidos por más de un mes y sometidos a proceso judicial. Por su parte, el gobierno de Evo Morales expresó que 
dichos soldados se encontraban realizando un operativo para desarticular un grupo dedicado al contrabando de autos, razón por la cual se extraviaron y cruzaron la frontera por error. Jorge Soria Quiroga, alcalde de lquique e histórico promotor de la paradiplomacia entre Chile y Bolivia por más de 50 años (Sánchez, 2016), tuvo una opinión similar, realizada en tercera persona, en la que rememora sus viajes a Oruro y en los que padece las mismas aprensiones sobre la frontera:

Si bien el edil [alcalde de la ciudad de lquique] respeta al pie de la letra las leyes que existen en Chile y Bolivia, cree que el Presidente podría resolver de forma pacífica el caso de los soldados bolivianos detenidos en la frontera. De hecho, rememoró como más de alguna vez él traspasó la frontera con sus caravanas de la integración. "En una oportunidad me tenían encañonado con las manos arriba", reveló.

¿Su sanción? No hubo pues las autoridades altiplánicas entendieron la misión que realizaba por sus caminos el alcalde de Iquique. "Entiendo que tanto los militares o policías chilenos actúen custodiando su territorio. Pero, cuando he transitado por Bolivia ellos me han visto como un hermano chileno que anda buscando potenciar sus caminos, valoró (Ilustre Municipalidad de lquique, 24 de febrero de 2013).

Ambos casos se resolvieron con la expulsión, no sin antes emplear palabras básicas que distancian a ambas sociedades por parte de las más altas autoridades de ambos países y quedan cuenta de la persistencia de identidades diplomáticas que se remontan a los albores de la relación chileno boliviana tras el fin de la Guerra del Pacífico y el tratado que selló sus vínculos desde 1904. No obstante, el uso de palabras básicas por parte del alcalde Soria que definen conceptos que permiten la integración entre actores regionales chilenos y bolivianos, como una salida al incidente diplomático descrito.

Llama la atención, respecto de la capacidad de referencia de la línea de frontera, que -en ambos casos- la discusión giró en torno de los escasos kilómetros que unos y otros se alejaron de sus respectivos hitos fronterizos, "adentrándose en el país vecino". Cuando en situaciones de "normalidad" equivocaciones como esas son habituales y nunca escalarían a incidente diplomático. En efecto, como señalamos al inicio, las identidades emotivista y del statu quo, exponen una particular fijación por el territorio nacional, entendido como un bloque de espacio uniforme, y en el que se expresa una fijación obsesiva por la frontera contigua y el límite. Así, territorio y soberanía se definen y exponen públicamente para quienes adhieren a esta identidad, remitiéndose a una definición unívoca, esto es, conceptos fijados en su significado y clausurados discursivamente, pese a ser esencialmente polémicos y exponer múltiples acepciones $^{10}$ (Guerrero, 2014:192 y ss.).

Un caso que -a pesar de su gravedad- no llegó a transformarse en un incidente diplomático como los mencionados, fue el asesinato de un coronel boliviano.

En 1943, después de un fallido golpe revolucionario contra Gualberto Villarroel, Presidente de Bolivia, el coronel boliviano Luis Brito, huyó hacia Chile llegando al poblado aymara de Caquena a unos 14 kilómetros de frontera, pensando que estaba en otro país y a salvo, sin embargo, fue alcanzado por un contingente de soldados bolivianos al mando del Coronel Barreno, quien lo ultimó (Urzúa 1964). Esta historia todavía se contaba en Caquena

10 Si bien se ha debatido marginalmente sobre mediterraneidad boliviana a partir de replantear la idea de soberanía, desde categorías como soberanías perforadas (Witker, 2004) o soberanías compartidas para administrar el territorio ariqueño (Anaya, 1987; Araníbar, 1999; Ovando, 2015), resulta complejo que se extienda dentro de las ciencias sociales chilenas más afines a la Cancillería y el Ministerio de Defensa. 
hasta hace un par de décadas. Sin embargo, el contexto histórico de 1943 era diferente de 1962, 1975 o 2017.

\section{Conclusiones.}

Este trabajo profundiza la cuestión de la identidad y sus formas en una región de frontera, discutiendo cómo se proyecta a través de contactos que trascienden la oficialidad estatal en las relaciones diplomáticas.

Con ello, intentamos contribuir al debate de las expresiones paradiplomáticas más allá de sus aportes funcionales al desarrollo de regiones periféricas, sin caer en la discusión sobre la formación de identidades separatistas o protodiplomacia, un debate que escapa a la realidad de América del Sur.

Así, el sentimiento de abandono que padecen muchas regiones periféricas lo que denominamos alienación territorial, siguiendo la discusión canadiense- contribuye a problematizar el sentido de las expresiones internacionales y transfronterizas que manifiestan muchos actores invisibilizados de la historia diplomática de Bolivia y Chile.

Por otro lado, en cuanto a los incidentes fronterizos que analizamos e interpretamos, que podrían calificarse de menores, según lo expresado, estos devienen en incidentes diplomáticos, debido a la ausencia de diálogo y porque la "definición de la situación" responde a identidades y acciones comunicativas diferentes. Carabaña y Lamo, siguiendo a Mead, nos dice que para que haya comunicación es necesario "que los símbolos utilizados signifiquen lo mismo, pero, para que signifiquen lo mismo, es necesario además que haya metacomunicación, es decir, que los sujetos hayan definido la situación del mismo modo" (1978:180). La ausencia de relaciones diplomáticas entre ambos países desde 1978, sin duda, ha disminuido los códigos compartidos para la resolución de conflictos, especialmente a escala de las cancillerías, generando no solo un estancamiento sino un retroceso en las relaciones transfronterizas. Si consideramos como referencia el Tratado de 1904, podemos concluir que hasta el presente (2017), Bolivia y Chile han tenido tantos años con relaciones diplomáticas como sin ellas.

Finalmente, para abordar la problemática fronteriza, tanto desde la dimensión histórica como paradiplomática actual, fue muy orientador el enfoque -a partir de Martin Buber- de emplear palabras básicas, tanto para identificar momentos de amistad como de hostilidad entre los actores estudiados. Por ejemplo, en un reciente artículo, titulado: "Bolivia no tiene mejor amigo que Chile, ni peor verdugo que el Perú: Dos cartas de Justiniano Sotomayor a Hilarión Daza, abril de 1879" (Ibarra 2018), observamos como la palabra básica amigoenemigo (Schmitt 1998), fue empleada por las elites boliviana y chilena en el origen de la guerra del Pacífico, para posteriormente ser también empleada por la elite peruana. El riesgo del uso de palabras básicas como la mencionada puede llevar a la deshumanización del otro, porque se suscita "la cuestión de quién es el que decide sobre lo bueno y lo malo" (Schmitt 1954:17). Este dilema ha sido recurrente a escala de las relaciones diplomáticas y de los actores nacionales, cuando esas relaciones son tensadas o los actores nacionales atraviesan un momento de crisis. En cambio, sostenemos que, a nivel de las relaciones paradiplomáticas, es 
posible romper la dualidad de la palabra básica, porque los actores subnacionales suelen tener elementos de identidad que les son propios, como historias, tradiciones y saberes comunes.
Un ejemplo de lo anterior ha sido la persistente relación de hermandad transfronteriza entre Oruro y Tarapacá durante todo el siglo veinte y el presente siglo.

\section{Bibliografía}

Albó, X., Arratia M, Núñez L., Hidalgo J., LLagostera A., Remy M. (1996) La Integración Surandina. Cinco siglos después. Centro de Estudios Regionales Andinos Bartolomé de Las Casas, Cuzco.

Aguirre, I. (2001). ¿Qué sentido tiene hablar de paradiplomacia? ¿Una encuesta intertextual en torno a un neologismo polisémico?, Paradiplomacia: las relaciones internacionales de las regiones en, Aldecoa F., y Michel Keating M, (dirs.). Madrid: Marcial Pons.203235

Ashley, R. (2009). "Desenredar el estado soberano: una doble lectura de la problemática de la anarquía", El constructivismo y las relaciones internacionales. Santa Cruz A. (Edit.). México: CIDE. 47-65

Amilhat Szary, A L. (2016). "Gentes y agentes, condiciones paradiplomáticas de la creación de una frontera móvil". Relaciones transfronterizas y paradiplomacia en América Latina: Aspectos teóricos y estudios de casos. González S., Cornago, N., Ovando, C. Santiago de Chile: Editorial RIL. 47-72.

Anaya, R. (1987). Arica Trinacional: Bolivia, Chile y Perú. La Paz: Editorial Lo amigos del libro

Andaluz, H. (2002). Bases jurídicas para la reintegración marítima de Bolivia: la regla pacta sunt servanda como punto cero. UPSA, Universidad Privada de Santa Cruz de la Sierra editores: Santa Cruz, Bolivia.

Araníbar, A. (1999) "Bolivia, Chile y Perú: Hacia un Futuro Compartido" La Paz, Bolivia: Plural editores.

Appadurai, A. (1996). "Sovereignty whitout territoriality: Notes for a postnational geography, en: Setha Low and Denise Lawrence (Edits.) The anthropology of space and place. Locating culture (pp.337-350). Malden, MA: Blackwell publishing.

Barros, M. (1970). Historia diplomática de Chile, 1541-1938, Ediciones Ariel, Barcelona.

Beck, U. (2002) La sociedad del riesgo global, Editorial Siglo $\mathrm{XXI}$, Madrid.

Boisier, S. (2003) "Globalización, geografía política y fronteras". Anales de Geografía de la Universidad Complutense 23: 21-39.

Bourdieu, P. (1994) Razones prácticas. Sobre la teoría de la acción. Barcelona: editorial Anagrama,

Buber, M. (2006) Yo y tú y otros ensayos. Buenos Aires: Editorial LILMOD

Cabrera L. (2009) "La relación bilateral Chile-Perú: un caso de visiones geopolíticas opuestas" Revista Encrucijada Americana. Año 3. $\mathrm{N}^{\circ} 1$.

Carabaña, J. y Lamo de Espinosa, E. (1978). "La Teoría social del Interaccionismo simbólico. Análisis y valoración crítica" Reis, 1: 159-203.

Chernilo, Daniel 2010 Nacionalismo y Cosmopolitismo. Ensayos Sociológicos Ediciones Universidad Diego Portales, Santiago.

Colacrai, M. y Lorenzini, M E. (2005). La política exterior de Chile: ¿excepcionalidad o continuidad? Una lectura combinada de fuerzas profundas y tendencias. Confines 1 (2): 45-63.

Constantinou, C. (2013). "Between Statecraft and Humanism: Diplomacy and Its Forms of Knowledge", International Studies Review 15:141-162.

Cornago, N. (2016b). "Diplomatic Knowledge", in: Costas Constantinou, Pauline Kerr and Paul Sharp The SAGE Handbook of Diplomacy (pp.133-141). Sage Publications: London.

Cornago N. (2016). "Diplomacia como heterología: pluralismo social y múltiples mediaciones institucionales en la frontera". Relaciones transfronterizas y paradiplomacia en América Latina: Aspectos teóricos y estudios de casos. González S., Cornago, N., Ovando, C. Santiago de Chile: Editorial RIL.17-46.

Cornago N. (2015) Introducción al postestructuralismo para internacionalistas, en: Celestino del Arenal y José Sanahuja (Edits.) Teorías de las relaciones internacionales (pp.219-237), Tecnos: Madrid.

Cornago, N. (2010). "La descentralización como elemento de innovación diplomática: aproximación a sus causas estructurales y lógicas de acción", La política internacional subnacional en América Latina. Maira. L. (Eds.). Buenos Aires, El Zorzal.107-134.

Duran, M. (2012). "The Transformation of Foreign Policy and Diplomacy Bridging the gap between Self and Other? Mediterranean paradiplomacy as homo-diplomacy". European Consortium of Political Research, ECPR Antwerp Joint Research Sessions, University of Antwerp, Belgium 10th - 15th April 2012.

Encina, F. (1963) Las relaciones entre Chile y Bolivia (1841-1963). Santiago: Editorial Nascimento.

Escobari, J. (1978). Historia diplomática de Bolivia. Tomo $1^{\circ}$ La Paz: Universidad Boliviana.

Francisco, M. (2009). "La cuestión Marítima en la política exterior de Chile y Bolivia”, Diplomacia 118: 47-69.

Guerrero, N. (2014) algunas reflexiones sobre el concepto "soberanía". Aportes para el debate de política exterior en Chile ESD. Estudios de Seguridad y Defensa 3:189-204.

Gibbins, R. (1980). Prairie Politics \& Society: Regionalism in Decline. Toronto: Butterworths. 
Giménez, G. (2009). "Cultura, identidad y memoria: Materiales para una sociología de los procesos culturales en las franjas fronterizas", Frontera Norte, 21(41): 7-32.

González, S, Ross, C, \& Ovando, C. (2016). "la cuestión del río Lauca" desde la perspectiva multiescalar: ¿un juego de suma cero de las diplomacias boliviana y chilena? Diálogo andino, (51), 57-72.

González, S y Ovando C. (2015) "El Abrazo de Charaña un breve instante que persiste en la historia de Arica" Estudios de Seguridad y Defensa 6: 15-40.

González, S. y Ovando, C. (2011). "La década dorada de las relaciones diplomáticas entre Chile y Bolivia", Tinkazos, 14(29), 87-108.

González, S. (2012). Sísifo en los Andes la (frustrada) integración física entre Tarapacá y Oruro: las caravanas de la amistad de 1958. Santiago de Chile: RIL.

González, S. (2011). "Las históricas relaciones entre Tarapacá y Oruro: la frustrada tentativa de integración transfronteriza durante ciclo de expansión del salitre (1864-1928)", Revista de geografía Norte Grande, (50), 63-85.

González Prada, M. (1941) Pensamientos. Tucumán: Ed. Americalee.

González Prada, M. (1976) Páginas Libres. Lima: Editorial Universo.

Guillaume, X. (2011). International Relations and Identity: A dialogical approach. Nueva York: Routledge Series.

Hansen, L. (2006). "Discourse Analysis, Post-Structuralism, and Foreign Policy", en: Smit, Steve, Hadfield, Amelia y Dunne, Tim (Eds.), Foreign Policy: Theories, Actors, Cases, $2^{a}$ ed., Oxford: Oxford University Press.

Harvey, D. (1985). Urbanismo y desigualdad social. Madrid: Siglo XXI.

Henry, S. (2000). Revisiting western alienation: Towards a better understanding of political alienation and political behaviour in western Canada, University of Calgar, Appears in Collections: University of Calgary Theses: 227-239

Heredia, E. (2005). "El Cono Sur, una región en el mundo, en: Pablo Lacoste (Edit.), 2005 Argentina, Chile y sus Vecinos, Tomo II, Caviar Bleu, Mendoza-Argentina: 167-189.

Hopf, T. (2002). Social Construction of International Politics: Identities and Foreign Policies. Estados Unidos: Cornell University Press.

Ibarra, P. (2018). "Bolivia no tiene mejor amigo que Chile, ni peor verdugo que el Perú: Dos cartas de Justiniano Sotomayor a Hilarión Daza, abril de 1879". Revista de Historia y Geografía N ${ }^{\circ}$ 38, 201-211.

Lawson R. (2005). "Understanding Alienation in Western Canada: Is "Western Alienation" the Problem? Is Senate Reform the Cure?" Journal of Canadian Studies, 39(2):127- 155.

Lebow, R. (2008). "Identity and International Relations", International Relations 22(4): 473-492.

Lefebvre, H. (1974). La production de l'espace. Paris: Anthropos.
Mitzen, J. (2006). Ontological Security in World Politics: State Identity and the Security Dilemma. European Journal of International Relations, 12(3),

341-370.

Morales, V. y Reyes, C. (2016). "Identidades compartidas: la centralidad de los lazos culturales como motor paradiplomático", Desafíos 28(1):79-120.

Morales, J. (2015). "Rusia como no-Europa: procesos de alterización en la construcción de una identidad de la UE, en política exterior". Ponencia presentada en XII Congreso de la Asociación Española de Ciencia Política y de la Administración (AECPA)GT 6.7 Relaciones Unión Europea - Federación Rusa: entre la rivalidad y la interdependencia Donostia/San Sebastián, 13 de julio de 2015.

Moreno, L. (2004),'Identidades múltiples y mesocomunidades globales', Globalización, gobernanza e identidades. Morata, F.; Lachapelle, G. and Paquin, S. (eds.). Barcelona: Fundació Carles Pi i Sunyer. 229-252.

Orias, R. (1997). "Derecho del mar y cooperación trinacional: una perspectiva boliviana”, en: Raúl Barrios (Edit.) Bolivia, Chile y Perú. Una opción cooperativa (pp.71-104). La Paz: Plural.

Ovando, C, y González, S. (2014). La relación bilateral chilenoboliviana a partir de las demandas tarapaqueñas: aproximación teórica desde la paradiplomacia como heterología. Estudios internacionales (Santiago), 46(177): 35-64.

Ovando, C. y González, S. (2012) «La política exterior chilenoboliviana en la década de 1950 mirada desde la región de Tarapacá: Una aproximación desde el diálogo entre las teorías de las percepciones y el realismo neoclásico». Polis, (11) 32:461-492.

Ovando, C. (2015). la noción de soberanía en las propuestas bolivianas para la salida al mar: el caso Arica trinacional. Diálogo andino, (48), 127-138

Paquin, S. (2004). Paradiplomatie et relations internacionales: Théorie des stratégies internationales des régions face à la mondialisation. Bruxelles: P.I.E.-Peter Lang.

Pintado, M. (2015). "Identidad y alteridad en un mundo en transformación. Un análisis de las relaciones entre China y Estados Unidos". Relaciones Internacionales 29.

Podestá, J. (2004). La invención de Tarapacá. Estado y desarrollo regional en Chile. Iquique: Ediciones Campus.

Ponce, J. (1998). Geopolítica chilena y mar boliviano La Paz: PGD Impresiones.

Querejazu, R. (1998) Guano, salitre, sangre. La paz: Librería editorial Juventud.

Rachik, A. (1995). Ville et pouvoirs au Maroc. Casablanca: Editions Afrique Orient.

Rodríguez I. (2015). "En los márgenes de la disciplina: feminismo y relaciones internacionales", Teorías de las relaciones internacionales. Del Arenal C. y Sanahuja J. (Edits.) Tecnos: Madrid. 243-267

Ross, C. (2016). La política chilena hacia Bolivia, 1900-1930: la constitución de un discurso estructural. Si Somos Americanos. Revista de Estudios Transfronterizos 16(1), 181-210. 
Ruz, R., Galdames, L., Díaz, A., Meza, M. (2006)

"Relatos visuales de una "Arica chilena". Los magazines de la editorial Zig-Zag (1902-1930)" Diálogo Andino 50:115-132.

Sahlins, P. (2000) "Repensando Boundaries". En: Alejandro Grimson (editor) Fronteras, Naciones e Identidades (pp. 41-49). Buenos Aires: Ediciones CICCUS La Crujía.

Salazar, F. (2006). Bolivia y Chile: desatando nudos: propuesta de salida al mar para Bolivia. La Paz: CERID- Plural.

Sánchez, R. (2016). "La acción internacional de Jorge Soria Quiroga, alcalde de la Municipalidad de Iquique. Paradiplomacia e imaginación geográfica, 1965-2015", Del hito a la apacheta Bolivia-Chile: Otra lectura de cien años de historia transfronteriza (1904-2004) en González S., Ovando C. y Bretón I. (Edits.), Editorial RIL: Santiago de Chile. 251-276

Sánchez, L y Zapata, V. (2014). "Una visión postestructuralista de la política exterior peronista. Las fuentes internas de su identidad", CONfines 10: 91-116.

Sarquís, D. (2013). "Fundamentos teóricos para la reflexión en torno a la paradiplomacia",. Teoría y práctica de la paradiplomacia. Zeraoui Z. (Edit.). México: Montiel y Soriano. 45-92.

Serje de la Ossa, M. (2017). Fronteras y periferias en la historia del capitalismo: el caso de América Latina. Revista de geografía Norte Grande, (66), 33-48.

Schmitt, C. (1954) "Coloquio sobre el poder y sobre el acceso al poderoso." Revista de Estudios Políticos 77 - 78 2): 3-20.

Schmitt, C. (1998) El concepto de lo político. Madrid: Alianza Editorial.

Soza-Amigo, S. \& Correa, L. (2014). Regiones extremas chilenas y su invisibilidad económica. Si Somos Americanos. Revista de Estudios Transfronterizos 14(2): 187-216.

Tavares, R. (2016). Paradiplomacy: Cities and States as Global Players. New York: Oxford University Press. XXI.

Todorov, T. (1991) Nosotros y los otros. México: Editorial Siglo

Urzúa, L. (1964) Arica, puerta nueva, Editorial Andrés Bello, Santiago.

Valenzuela, E. (1999). Alegato histórico regionalista. Santiago: Sur Editores.

Véliz, C. (1980) La tradición centralista de América Latina; ed. inglesa previa. Princeton University Press. Princeton New Jersey

Walker, R. B.J. (1995). Relaciones internacionales y política mundial, Postmodernismo y relaciones internacionales. Nasi C. (Comp.): heBogotá: Universidad Nacional. 53-78

Walker, R.B.J. (1993). Inside/Outside: Intemational Relations as Political Theory, Cambridge: Cambridge University Press.

Witker, I. (2004) "Mediterraneidad, soberanía y paradiplomacia: tres ejes de discusión teórica para la Problemática chilenoboliviana". . Bolivia-Chile: Propuestas de integración para el siglo XXI. Tapia. M. Inte-Unap/Gobierno Regional de Tarapacá, Iquique, Chile. 27-51.

Zeraoui, Z. (2016). Para entender la paradiplomacia. Desafíos, 28(1), 15-34.

\section{Diarios citados y fuentes electrónicas.}

El Tarapacá de lquique, del lunes 26 de mayo de 1958.

La Defensa de Arica del 3 de mayo de 1962.

La Defensa de Arica, del lunes 13 de enero de 1975.

Ilustre Municipalidad de lquique, Alcalde conversó de amistad e integración con diputados bolivianos24 de febrero de 2013 Disponible en:http://www.municipioiquique.cl/2013/02/24/ alcalde-converso-de-amistad-e-integracion-con-diputadosbolivianos/ (consultado el 12 de mayo de 2018). 